which must have gripped the first students of wolf communication as they began to comprehend a language of hackles, ears and tails. Some readers might be unintentionally misled by passages such as 'It is one of the oddities of our age that much of what Eskimos know about wolves ... wildlife biologists are still intent on discovering'. Lopez describes the almost magical abilities of Eskimos to find, track and intercept wolves, and finds these same abilities wanting in some biologists concerned with predator control. I am sure that he has not concluded that these are general failings of the science, but his reader might! If biologists have ignored the spirit of the wolf, of its mental experiences, this is not necessarily because they judge these things to be uninteresting or non-existent, but because they have no method for better understanding them. In summary, I enjoyed $O f W o l v e s$ and $M e n$, and I enjoyed it more the more I read it.

The coyote book is quite different (and costs over twice as much per page). A book for the specialist, it will doubtless be thoroughly read by all who study canids. The 15 chapters, each by a different authority, cover such major sections as evolution, pathology, behaviour, ecology, systematics and management. One of these serves well to illustrate just how much detail and insight a perceptive field biologist can gain. In Franz Camenzind's account of the coyotes of the National Elk Refuge one learns much of the subtle flexibility of coyote society, with gripping and theoretically important observations on the relationships within and between coyote groups.

Like the wolf, the coyote has been the subject of considerable persecution in North America. The section on Management reviews published information of the significance of the coyote as pest, the effectiveness of conventional and developing control methods and the general future of the coyotes' relationships with men. All these reviews end on rather pessimistic notes, irrespective of one's stance on predator control, since none foresee any changes in philosophy or methodology in the near future, but the point is made, and this is important, that new thinking in wildlife management rests on gradually accumulating understanding of species' biology, behaviour and ecology.

DAVID W. MACDONALD

Eric Hosking's Birds. Pelham Books, $£ 10.50$.

The Scottish Ospreys, by Philip Brown. Heinemann, $\mathfrak{1 7 . 5 0}$.

When I met Eric Hosking 25 years ago in the Coto Donana he had already been a professional bird photographer for another 25 years. Thus, as the world's first full-time wildlife photographer, he has devoted his whole adult life to developing what was his boyhood hobby. The text of Eric Hosking's Birds, written with the help of Kevin MacDonnell, is a mixture of anecdote, bird-lore and photographic technicalities, but essentially it is a picture book. And what pictures! They are the pick of a half-century's harvest, 200 in black and white and 80 in colour, admirably reproduced. A reluctant traveller, Hosking stuck to British birds until halfway through his career, since when he has roamed across five continents with his cameras, even visiting the remote Galapagos where, to a man of his skills, photographing the 'amazingly unconcerned wildlife' must have seemed rather like shooting sitting ducks. In a foreword, Roger Tory Peterson concludes that, as a bird photographer, Hosking 'has no peer'; and few readers are likely to contest his verdict.

The Scottish Ospreys also contains some splendid illustrations, but the book is built around the story of the RSPB's re-establishment of the osprey as a breeding bird at Loch Garten. The opening chapters give a general account of ospreys and a documented history of their extirpation in Scotland in the days when hardly anyone cared. Then Philip Brown gives a round-by-round account of that ornithological cliffhanger, Operation Osprey, with its alternating hopes and frustrations. Under the command of George Waterston, a band of enthusiasts struggled for years until their obstinacy finally overcame repeated disappointments, and the osprey was restored to the British list of breeding birds. Success was followed by the daring decision to invite the public into the 
peep-show, and the tally of spectators at the nesting site must now be nearing the million mark.

This RSPB triumph was primarily due to the faith and courage of a small group of dedicated conservationists, but it would have been impossible without a very considerable expenditure of manpower and money. I cannot help thinking that a comparable expenditure of resources in some poor country might have saved a whole doomed habitat and not just a few members of one species, which was not universally endangered. This is not meant even remotely as a criticism. I know that I am not comparing like with like and that gifts left by Loch Garten visitors must have handsomely covered the outlay. But the greatest value of this success story, quite apart from boosting RSPB membership, would be if it provided inspiration to devote equal efforts to more important projects further from home. Time is not on the side of conservation, so it is little comfort to recall that Operation Osprey could not have been mounted 50 years earlier. In their different ways, these two books do illustrate the growing concern for wildlife, even if indirectly they demonstrate the need to quicken our pace, widen our horizons, and dig deeper into our pockets.

G.T. CORLEY SMITH

\section{The Tidal Thames: The History of a River and Its Fishes, by Alwyne Wheeler. Routledge, $£ 8.95$.}

The cleansing of the polluted Thames is one of the great conservation successes of the last half of the century. In The Thames Transformed the late Jeffrey Harrison and Peter Grant described its impact on the bird population of the Thames estuary. Now Alwyne Wheeler of the British Museum (Natural History) tells the story from the angle of the fish populations. From a time when there were virtually no fish in the river between Richmond and Gravesend, we have reached a period when some fish can be caught by anglers throughout this once highly polluted stretch. The first part of the book describes how the river became progressively polluted by sewage and industrial discharge during and after the Industrial Revolution and how the once rich fisheries of the estuary were destroyed. With the post-war decision to clean the river up, the author is able to chronicle the gradual recolonisation of the river below Teddington Lock. Today the smelt is once more a common fish, and salmon and sea trout are beginning to re-enter the estuary. The last part of the book describes the new status of each fish, freshwater, migratory and marine.

This is a fine book that deserves to be widely read. The Thames Water Authority ought to distribute it widely to show what can be done.

R.S.R. FITTER

\section{The Sinking Ark, by Norman Myers. Pergamon, $£ 4.50$.}

As Norman Myers rightly says in his very first line: "This is not the first book on disappearing species'. The difference with this one, he claims, is that it takes the theme further, by looking at the prospects for all species and by asking why species are being allowed to disappear. On the first point, instead of the traditional cry that we are losing one species a year, Myers suggests that it may be one a day, bearing in mind the 5-10 million thought to exist. On the second point he feels we should examine (and he does) every aspect impinging upon species disappearance, such as the political, economic, legal, social and cultural sides of the question.

The result is a very well thought-out book. Its chapters, with all their sub-headings, have been arranged extremely academically. Most of the subjects that he discusses, however important, have only a single index entry, a sure sign of advanced planning. In essence, the book has three sections: the problem in general, the tropical forests in particular, and conservation strategies that should be adopted to deal with them. The last section is, alas, the shortest, as those of us who are already converted (and who read Oryx) know the problems well enough but are lacking in solutions. I would like to have 